\title{
Trends and Topics in Educational Technology, 2022 Edition
}

\author{
Royce Kimmons ${ }^{1}$. Joshua M. Rosenberg ${ }^{2}$ \\ Published online: 23 February 2022 \\ (c) Association for Educational Communications \& Technology 2022
}

This editorial continues our annual effort to identify and catalog trends and popular topics in the field of educational technology. Continuing our approach from previous years (Kimmons, 2020; Kimmons et al., 2021), we use public internet data mining methods (Kimmons \& Veletsianos, 2018) to extract and analyze data from three large data sources: the Scopus research article database, the Twitter \#edtech affinity group, and school and school district Facebook pages. Such data sources can provide valuable insights into what is happening and what is of interest in the field as educators, researchers, and students grapple with crises and the rapidly evolving uses of educational technologies (e.g., Kimmons et al., 2020; Trust et al., 2020; Veletsianos \& Kimmons, 2020). Through this analysis, we provide a brief snapshot of what the educational technology field looked like in 2021 via each of these lenses and attempt to triangulate an overall state of our field and vision for what may be coming next.

\section{What Were Trending Topics in Educational Technology Journals in 2021?}

Educational technology research topics for 2021 were very similar to previous years, with a few exceptions. In total, we collected titles for 2368 articles via Scopus published in top educational technology journals as identified by Google Scholar. We then analyzed keyword and bigram (two words found together) frequencies in titles to determine the most commonly referenced terms. To assist in making sense of results, we also manually grouped together keywords and bigrams into four information types: contexts, methods,

\footnotetext{
Royce Kimmons

roycekimmons@byu.edu

Joshua M. Rosenberg

jmrosenberg@utk.edu

Brigham Young University, Provo, UT, USA

2 University of Tennessee, Knoxville, TN, USA
}

modalities, and topics. Contexts included terms referring to the research setting, such as "COVID-19" or "higher education." Methods included terms referring to research methods involved in the article, such as "systematic review" or "meta-analysis." Modalities included terms referring to the technical modality through which the study was occurring, such as "virtual reality" or "online learning." Last, Topics included terms referring to the intervention, objective, or theoretical goal of the study, such as "computational thinking," "learning environment," or "language learning." The most common bigrams and keywords for each type may be found in Table 1; a few items of interest follow.

Bigrams generally provide more specificity for interpreting meaning than do keywords, simply because keywords might have greater variety in usage (e.g., "school" might be used in the context of "primary school," "secondary school," "school teacher," and so forth). So, when interpreting Table 1, the bigram column is generally more useful for identifying trending topics, though the keyword column may at times be helpful as a clarifying supplement.

"Computational thinking" and "learning environments" were the two most-researched topical bigrams in 2021, and "virtual reality" and "online learning" were the mostresearched modality bigrams. Most-referenced methods included "systematic review" and "meta-analysis," which is noteworthy because such methods are used to conduct secondary analyses on existing studies, and their dominance may suggest an interest in the field to identify what works and to synthesize findings across various contexts within a sea of articles that is ever-increasing in size.

Due to the ongoing COVID-19 pandemic, this contextual term was regularly mentioned in many article titles (5.4\%). "Pandemic" (3.4\%), "emergency" (1.2\%), and "shift to" (e.g., digital, online, blended; $0.9 \%$ ) were also commonly referenced. This suggests that as the world continues to grapple with this multifaceted crisis, educational technology researchers are heavily engaged in addressing educational concerns associated with it (and remote teaching, particularly). 
Table 1 Most Popular Educational Technology Title Bigrams and Keywords by Type

\begin{tabular}{|c|c|c|c|c|c|}
\hline Bigram & $n$ & $\%$ & Keyword & $n$ & $\%$ \\
\hline \multicolumn{6}{|c|}{ Contexts } \\
\hline covid +19 & 128 & $5.4 \%$ & school* ${ }^{*}$ & 140 & $5.9 \%$ \\
\hline high $*+$ education $*$ & 83 & $3.5 \%$ & high* & 130 & $5.5 \%$ \\
\hline university+student* & 45 & $1.9 \%$ & covid-19 & 128 & $5.4 \%$ \\
\hline school $*+$ student $*$ & 40 & $1.7 \%$ & classroom* & 97 & $4.1 \%$ \\
\hline $\mathrm{k}+12$ & 40 & $1.7 \%$ & university & 83 & $3.5 \%$ \\
\hline pre + service & 31 & $1.3 \%$ & pandemic & 79 & $3.4 \%$ \\
\hline high $^{*}+$ school $^{*}$ & 26 & $1.1 \%$ & academic* & 78 & $3.3 \%$ \\
\hline primary+school $*$ & 24 & $1.0 \%$ & course & 76 & $3.2 \%$ \\
\hline secondary+school* & 19 & $0.8 \%$ & writ* & 59 & $2.5 \%$ \\
\hline \multicolumn{6}{|c|}{ Methods } \\
\hline systematic+review* & 50 & $2.1 \%$ & design* & 187 & $7.9 \%$ \\
\hline meta+analysis & 36 & $1.5 \%$ & study* & 161 & $6.8 \%$ \\
\hline evaluation+of & 28 & $1.2 \%$ & review* & 144 & $6.1 \%$ \\
\hline literature+review* & 26 & $1.1 \%$ & self & 114 & $4.8 \%$ \\
\hline influence+of & 24 & $1.0 \%$ & perception* & 81 & $3.4 \%$ \\
\hline case+study* & 24 & $1.0 \%$ & assessment* & 78 & $3.3 \%$ \\
\hline \multicolumn{6}{|c|}{ Modalities } \\
\hline virtual+reality & 71 & $3.0 \%$ & online & 305 & $12.9 \%$ \\
\hline online+learn* & 69 & $2.9 \%$ & virtual & 135 & $5.7 \%$ \\
\hline augment* + reality & 33 & $1.4 \%$ & mobile & 109 & $4.6 \%$ \\
\hline blended+learn* & 33 & $1.4 \%$ & video* & 66 & $2.8 \%$ \\
\hline mobile+learn* & 26 & $1.1 \%$ & blended & 57 & $2.4 \%$ \\
\hline shift* + to & 21 & $0.9 \%$ & elearn* & 52 & $2.2 \%$ \\
\hline distance+learn* & 21 & $0.9 \%$ & flipped & 50 & $2.1 \%$ \\
\hline flipped+learn* & 19 & $0.8 \%$ & remote & 45 & $1.9 \%$ \\
\hline online+courses & 19 & $0.8 \%$ & augment* & 45 & $1.9 \%$ \\
\hline flipped+classroom* & 19 & $0.8 \%$ & distance & 40 & $1.7 \%$ \\
\hline \multicolumn{6}{|c|}{ Topics } \\
\hline computational+think $*$ & 59 & $2.5 \%$ & environment* & 133 & $5.6 \%$ \\
\hline learn*+environment $*$ & 54 & $2.3 \%$ & model $*$ & 133 & $5.6 \%$ \\
\hline game+based & 43 & $1.8 \%$ & system* & 130 & $5.5 \%$ \\
\hline language+learn* & 36 & $1.5 \%$ & performance & 123 & $5.2 \%$ \\
\hline self+efficacy & 33 & $1.4 \%$ & reality & 121 & $5.1 \%$ \\
\hline social+media & 31 & $1.3 \%$ & language & 109 & $4.6 \%$ \\
\hline student ${ }^{*}+$ engagement & 26 & $1.1 \%$ & social & 102 & $4.3 \%$ \\
\hline student $*+$ perception $*$ & 26 & $1.1 \%$ & think* & 97 & $4.1 \%$ \\
\hline foreign+language & 26 & $1.1 \%$ & game & 97 & $4.1 \%$ \\
\hline education $*+$ technology & 26 & $1.1 \%$ & engagement & 95 & $4.0 \%$ \\
\hline learn* + analytic* & 24 & $1.0 \%$ & comput* & 92 & $3.9 \%$ \\
\hline cognitive+load & 21 & $0.9 \%$ & skill* & 90 & $3.8 \%$ \\
\hline artificial+intelligence & 21 & $0.9 \%$ & collaborative & 85 & $3.6 \%$ \\
\hline learn $*+$ analytics & 21 & $0.9 \%$ & instruction* & 83 & $3.5 \%$ \\
\hline self+regulat* & 21 & $0.9 \%$ & motivation* & 69 & $2.9 \%$ \\
\hline learn* + outcomes & 21 & $0.9 \%$ & knowledge & 69 & $2.9 \%$ \\
\hline
\end{tabular}

Grade level references in titles further suggested that educational technology research is being conducted at all levels but that it is most prominent at the higher education or postsecondary level and reduces in frequency as grade levels go down, with high school or secondary terms being more prominent than elementary or primary terms, with "higher education" (3.5\%) being referenced twice as frequently as "K-12" $(1.7 \%)$. This is noteworthy as it suggests that research findings associated with educational technology are currently mainly focused on older (and even adult) students and that if results are applied to understanding learners generally, then the needs of adolescents and younger children may currently be relatively underrepresented.

\section{What Were Trending \#Edtech Topics and Tools on Twitter in 2021?}

Twitter is a valuable source of information about trends in a field because it allows researchers and practitioners to share relevant resources, studies, and musings and categorize posts via descriptive hashtags. The \#edtech hashtag continued to be very popular during 2021, and we collected all original tweets (ignoring retweets) that included the \#edtech hashtag for the year. This included 433,078 original tweets posted by 40,767 users, averaging 36,090 tweets per month $(S D=2974)$.

Because users can include multiple hashtags on a tweet, we aggregated the frequencies of additional (co-occurring) hashtags to determine the intended audiences (e.g., \#teachers, \#k12) and content topics (e.g., \#elearning, \#ai) of tweets. Some of the most popular additional hashtags of each type are presented in Table 2. To better understand results, we also calculated the representation of each additional hashtag in the overall dataset (e.g., $2 \%$ of all \#edtech tweets also included the \#teachers hashtag) and the diversity of authorship (i.e., the number of users divided by the number of tweets). This diversity score was helpful for understanding how some hashtags were used by relatively few accounts for purposes such as product promotion. For example, the \#byjus hashtag, which refers to an educational technology company founded in India, was tweeted 19,546 times. Still, the diversity score was only $3 \%$, revealing that though this was a very popular hashtag in terms of tweet counts, it was being included by relatively few accounts at very high frequencies, such as via focused marketing campaigns.

Notably, several community or affinity space hashtags (Carpenter \& Krutka, 2014; Rosenberg et al., 2016) were among the most common included with \#edtech, such as \#edchat, \#edutwitter, and \#teachertwitter. In particular, $13.9 \%$ of \#edtech tweets also were tagged as \#educhat, and $25.7 \%$ of \#educhat tweets were also tagged as \#edtech, revealing relatively high synchronicity between these two 
Table 2 Most Popular Additional Hashtags in \#edtech Tweets by Type

\begin{tabular}{|c|c|c|c|c|}
\hline Hashtag & Users & Tweets & Representation & Diversity \\
\hline \multicolumn{5}{|c|}{ Audience, Community, or Affinity Space } \\
\hline edchat & 3600 & 60,252 & $14 \%$ & $6 \%$ \\
\hline edutwitter & 2249 & 14,669 & $3 \%$ & $15 \%$ \\
\hline teachers & 2206 & 10,155 & $2 \%$ & $22 \%$ \\
\hline edtechchat & 1856 & 17,922 & $4 \%$ & $10 \%$ \\
\hline students & 1818 & 8025 & $2 \%$ & $23 \%$ \\
\hline highered & 1770 & 14,013 & $3 \%$ & $13 \%$ \\
\hline k12 & 1712 & 25,500 & $6 \%$ & $7 \%$ \\
\hline school & 1284 & 9419 & $2 \%$ & $14 \%$ \\
\hline highereducation & 1161 & 4715 & $1 \%$ & $25 \%$ \\
\hline teacher & 1034 & 4824 & $1 \%$ & $21 \%$ \\
\hline teachertwitter & 1026 & 6861 & $2 \%$ & $15 \%$ \\
\hline schools & 995 & 5578 & $1 \%$ & $18 \%$ \\
\hline educators & 850 & 3440 & $1 \%$ & $25 \%$ \\
\hline \multicolumn{5}{|c|}{ Topic } \\
\hline education & 9374 & 93,459 & $22 \%$ & $10 \%$ \\
\hline learning & 3896 & 25,909 & $6 \%$ & $15 \%$ \\
\hline elearning & 2875 & 27,816 & $6 \%$ & $10 \%$ \\
\hline onlinelearning & 2681 & 12,423 & $3 \%$ & $22 \%$ \\
\hline technology & 2577 & 10,826 & $2 \%$ & $24 \%$ \\
\hline remotelearning & 2380 & 10,732 & $2 \%$ & $22 \%$ \\
\hline ai & 2112 & 11,323 & $3 \%$ & $19 \%$ \\
\hline stem & 1913 & 15,760 & $4 \%$ & $12 \%$ \\
\hline teaching & 1869 & 15,146 & $3 \%$ & $12 \%$ \\
\hline innovation & 1705 & 6915 & $2 \%$ & $25 \%$ \\
\hline startup & 1690 & 6950 & $2 \%$ & $24 \%$ \\
\hline tech & 1537 & 7139 & $2 \%$ & $22 \%$ \\
\hline startups & 1393 & 3730 & $1 \%$ & $37 \%$ \\
\hline coding & 1032 & 4252 & $1 \%$ & $24 \%$ \\
\hline distancelearning & 1022 & 5601 & $1 \%$ & $18 \%$ \\
\hline $\mathrm{vr}$ & 917 & 4368 & $1 \%$ & $21 \%$ \\
\hline covid19 & 906 & 3831 & $1 \%$ & $24 \%$ \\
\hline fintech & 895 & 3335 & $1 \%$ & $27 \%$ \\
\hline virtuallearning & 872 & 2769 & $1 \%$ & $31 \%$ \\
\hline digitaltransformation & 851 & 3215 & $1 \%$ & $26 \%$ \\
\hline digitallearning & 841 & 4021 & $1 \%$ & $21 \%$ \\
\hline cybersecurity & 820 & 3111 & $1 \%$ & $26 \%$ \\
\hline blendedlearning & 781 & 4268 & $1 \%$ & $18 \%$ \\
\hline
\end{tabular}

spaces. Furthermore, regarding institutional level, \#k12 $(n=1712)$ and \#highered $(n=1770)$ exhibited similar user counts, as did \#school $(n=1284)$ and \#highereducation ( $n=1161)$, but, interestingly, the \#k12 and \#school hashtags exhibited nearly twice as many tweets as their \#highered and \#highereducation counterparts. This suggests that although the communities tweeting about topics for each group may be of similar size, the K-12 community was much more active than the higher education community.
Regarding topics, \#elearning, \#onlinelearning, \#remotelearning, \#distancelearning, \#virtuallearning, and \#blendedlearning were represented at a relatively high rate (in $16.1 \%$ of tweets), perhaps reflecting ongoing interest associated with \#covid19. Other prominent topical hashtags included emerging technologies, such as \#ai $(n=2112)$, \#vr $(n=917)$, \#ar $(n=679)$, and \#blockchain $(n=545)$, as well as subject areas (e.g., \#stem) and general descriptors (e.g., \#innovation).

Furthermore, one of the primary reasons for tweeting is to share resources or media items. An analysis of these \#edtech tweets revealed that $94.4 \%$ included either a link to an external site or an embedded media resource, such as an image or video. Regarding external links, prominent domains included (a) news sites, such as edsurge.com, edtec hmagazine.com, or edutopia.org, (b) other social media, such as linkedin.com, instagram.com, or facebook.com, (c) multimedia resources, such as youtube.com, anchor.fm, or podcasts.apple.com, and (d) productivity and management tools, such as docs.google.com, forms.gle, or eventbrite.com (cf., Table 3).

Twitter communications in 2021 regarding \#edtech included chatter about a variety of topics and resources. Shadows of \#COVID-19 might be detected in the prevalence of this hashtag with others, like \#remotelearning and \#onlinelearning, but in many ways it seems that conversations continued to focus on issues of \#education and \#learning, as well as emerging topics like \#ai, \#vr, and \#cybersecurity, suggesting some level of imperviousness to the pandemic.

\section{What Were Trending Topics among Schools and School Districts on Facebook in 2021?}

To examine trending educational technology topics on Facebook, we studied the posts by 14,481 schools and school districts on their public pages. First, one aspect of this analysis concerned the number of posts shared. In our last report, we documented how schools and districts posted more posts than in any other month during March, April, and May 2020 — during the earliest and perhaps most tumultuous months of the COVID-19 pandemic, suggesting the importance of communication during this crisis period, as others have documented with Twitter data (Michela et al., 2022). Notably, in 2021, those months remained the most active; apart from those months, the numbers of posts by schools and districts in 2021 were roughly comparable to the numbers in 2019 and 2020 (see Fig. 1).

To understand which technologies were shared on these Facebook pages, we examined the domain names for all of the hyperlinks that were posted. Despite the myriad social and other changes experienced by schools from 2019 to 
Table 3 Most Common External Link Domains Referenced in \#edtech Tweets

\begin{tabular}{|c|c|c|}
\hline Domain & Users & Tweets \\
\hline edsurge.com & 2879 & 6588 \\
\hline youtube.com & 2595 & 12,402 \\
\hline linkedin.com & 475 & 1142 \\
\hline edtechmagazine.com & 316 & 1463 \\
\hline instagram.com & 302 & 511 \\
\hline edutopia.org & 281 & 762 \\
\hline docs.google.com & 276 & 681 \\
\hline techcrunch.com & 270 & 646 \\
\hline forbes.com & 251 & 473 \\
\hline facebook.com & 170 & 338 \\
\hline forms.gle & 159 & 248 \\
\hline medium.com & 155 & 503 \\
\hline yourstory.com & 155 & 1238 \\
\hline link.medium.com & 149 & 268 \\
\hline edweek.org & 140 & 438 \\
\hline eschoolnews.com & 138 & 595 \\
\hline shakeuplearning.com & 131 & 3344 \\
\hline eventbrite.com & 130 & 232 \\
\hline edtechnology.co.uk & 126 & 318 \\
\hline eventbrite.co.uk & 126 & 532 \\
\hline anchor.fm & 125 & 496 \\
\hline podcasts.apple.com & 123 & 223 \\
\hline livemint.com & 117 & 626 \\
\hline techlearning.com & 116 & 332 \\
\hline sites.google.com & 115 & 193 \\
\hline vmukta.com & 114 & 546 \\
\hline economictimes.indiatimes.com & 110 & 908 \\
\hline drive.google.com & 108 & 196 \\
\hline
\end{tabular}

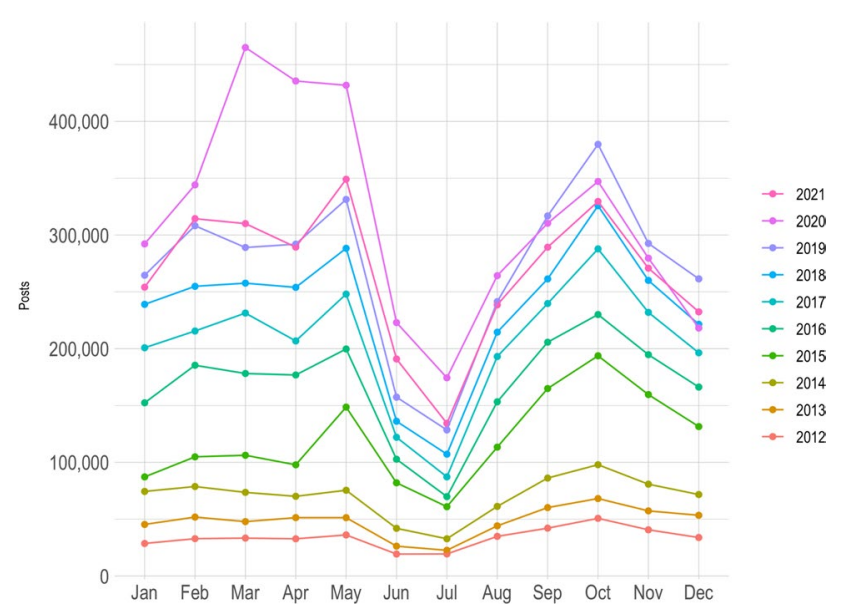

Fig. 1 The Number of Posts on Facebook by Schools and School Districts
2021, link domains shared on Facebook exhibited remarkable consistency: Youtube, Google Docs, Google, and Google Drive-Google or tools created by Google-were the four most frequently shared for each of these years (Table 4). Note that the $n$ represents the number of schools or districts sharing one or more links to these domains (of the 14,481 total school and school district pages). Thus, the 8278 indicates that $57.2 \%$ of schools and districts posted one or more links to YouTube over the 2021 year. These were followed by Zoom, which was also widely shared in 2020 (though not in 2019), and then Google Sites (which was shared frequently in 2020). The CDC and 2020 Census's websites dropped from the list of the top ten most frequently shared domains in 2021, despite having been widely shared in 2020 . Otherwise, the results are largely comparable between 2019 , 2020 , and 2021, indicating that schools and districts continued to use a core set of productivity tools despite the many disruptions and changes over this period.

We also examined the contents of the messages of schools' and school districts' posts. To do so, we considered the technologies identified by Weller (2020) in his history of the past 25 years of educational technology, as in our report for last year. Specifically, we searched the contents of the messages posted by schools and districts for the inclusion of the terms that correspond to technologies Weller identified as being representative of a particular year. While the domains shared by schools and districts demonstrated remarkable consistency, the contents of the messages posted by schools and districts varied substantially, especially when considering the changes from 2019 to 2020 and from 2020 to 2021. To illustrate, consider mentions of "e-learning," which Weller identified as the focal point of 1999. In 2019, 834 messages that mentioned "e-learning" were posted by schools and districts, but in 2020, the number increased around ten-fold to 8326 mentions. Though it may have been expected for mentions of "e-learning" to remain somewhat constant during 2021, instead we saw a marked downturn to 1899 (or a 78\% drop). This trend-a sizable increase in how often certain technologies were mentioned in 2020 relative to 2019 that was not sustained in 2021—was also found for mentions of "learning management systems," "video," and "Second Life and virtual worlds," among others. Indeed, the only noteworthy increase in mentions of these technologies from 2020 to 2021 was for "artificial intelligence".

\begin{tabular}{|c|c|c|c|c|}
\hline Topic & 2019 & 2020 & 2021 & Total \\
\hline $\begin{array}{l}\text { 1994: Bulletin Board } \\
\text { Systems }\end{array}$ & 0 & 0 & 0 & 2 \\
\hline 1995: The Web & 4953 & 12,269 & 8001 & 50,750 \\
\hline $\begin{array}{l}\text { 1996: Computer- } \\
\text { Mediated Com- } \\
\text { munication }\end{array}$ & 0 & 0 & 0 & 1 \\
\hline
\end{tabular}


Table 4 Domains for Hyperlinks Shared on School and School District Facebook Pages

\begin{tabular}{|c|c|c|c|c|c|}
\hline \multicolumn{2}{|l|}{2019} & \multicolumn{2}{|l|}{2020} & \multicolumn{2}{|l|}{2021} \\
\hline Domain & $n$ & Domain & $n$ & Domain & $n$ \\
\hline youtube.com & 5117 & youtube.com & 10,261 & youtube.com & 8278 \\
\hline docs.google.com & 4557 & docs.google.com & 10,033 & docs.google.com & 7662 \\
\hline google.com & 3198 & google.com & 9861 & google.com & 4969 \\
\hline drive.google.com & 2082 & drive.google.com & 5616 & drive.google.com & 3688 \\
\hline surveymonkey.com & 1513 & zoom.us & 4563 & zoom.us & 3198 \\
\hline signupgenius.com & 1441 & accounts.google.com & 3718 & accounts.google.com & 2616 \\
\hline eventbrite.com & 1299 & sites.google.com & 3469 & sites.google.com & 2043 \\
\hline bookfairs.scholastic.com & 996 & cdc.gov & 2475 & signupgenius.com & 1529 \\
\hline vimeo.com & 985 & surveymonkey.com & 2236 & nfhsnetwork.com & 1512 \\
\hline smore.com & 890 & bookfairs.scholastic.com & 1817 & smore.com & 1508 \\
\hline sites.google.com & 877 & smore.com & 1786 & bookfairs.scholastic.com & 1456 \\
\hline accounts.google.com & 798 & vimeo.com & 1626 & surveymonkey.com & 1442 \\
\hline applitrack.com & 634 & 2020census.gov & 1455 & gofan.co & 1288 \\
\hline gofundme.com & 452 & signupgenius.com & 1421 & vimeo.com & 1203 \\
\hline mailchi.mp & 452 & eventbrite.com & 1225 & eventbrite.com & 1190 \\
\hline
\end{tabular}

\begin{tabular}{|c|c|c|c|c|}
\hline Topic & 2019 & 2020 & 2021 & Total \\
\hline $\begin{array}{l}\text { 1997: Constructiv- } \\
\text { ism }\end{array}$ & 1 & 3 & 0 & 25 \\
\hline 1998: Wikis & 515 & 736 & 584 & 4172 \\
\hline 1999: E-Learning & 834 & 8362 & 1899 & 13,136 \\
\hline $\begin{array}{l}\text { 2000: Learning } \\
\text { Objects }\end{array}$ & 81 & 77 & 76 & 471 \\
\hline $\begin{array}{l}\text { 2001: E-Learning } \\
\text { Standards }\end{array}$ & 0 & 0 & 0 & 0 \\
\hline $\begin{array}{l}\text { 2002: Learning } \\
\text { Management } \\
\text { Systems }\end{array}$ & 79 & 719 & 221 & 1316 \\
\hline 2003: Blogs & 33,583 & 35,469 & 30,808 & 247,606 \\
\hline $\begin{array}{l}\text { 2004: Open Educa- } \\
\text { tional Resources }\end{array}$ & 5 & 4 & 24 & 63 \\
\hline 2005: Video & 41,493 & 116,985 & 55,829 & 395,100 \\
\hline 2006: Web 2.0 & 1 & 1 & 0 & 62 \\
\hline $\begin{array}{l}\text { 2007: Second Life } \\
\text { and Virtual Worlds }\end{array}$ & 32 & 301 & 122 & 564 \\
\hline 2008: E-Portfolios & 7 & 6 & 2 & 59 \\
\hline $\begin{array}{l}\text { 2009: Twitter and } \\
\text { Social Media }\end{array}$ & 9266 & 20,459 & 11,927 & 66,345 \\
\hline 2010: Connectivism & 0 & 0 & 0 & 0 \\
\hline $\begin{array}{l}\text { 2011: Personal } \\
\text { Learning Environ- } \\
\text { ments }\end{array}$ & 0 & 0 & 0 & 9 \\
\hline $\begin{array}{l}\text { 2012: Massive Open } \\
\text { Online Courses }\end{array}$ & 1 & 1 & 0 & 17 \\
\hline $\begin{array}{l}\text { 2013: Open Text- } \\
\text { books }\end{array}$ & 4 & 1 & 0 & 6 \\
\hline $\begin{array}{l}\text { 2014: Learning } \\
\text { Analytics }\end{array}$ & 0 & 3 & 3 & 19 \\
\hline 2015: Digital Badges & 35 & 29 & 29 & 166 \\
\hline $\begin{array}{l}\text { 2016: Artificial } \\
\text { Intelligence }\end{array}$ & 119 & 98 & 127 & 511 \\
\hline
\end{tabular}

\begin{tabular}{lllll}
\hline Topic & 2019 & 2020 & 2021 & Total \\
\hline $\begin{array}{l}\text { 2017: Blockchain } \\
\text { Total }\end{array}$ & 14 & 12 & 17 & 78 \\
\hline
\end{tabular}

\section{Summary and Discussion}

By triangulating the 2021 snapshots of each of these three data sources-Scopus, Twitter, and Facebook-we can begin to see a state of the educational technology field pressing into the future. Results on specific terms or topics may be useful for individual researchers and practitioners to see the representation of their areas of interest. Still, some common takeaways that emerge from all three sources include the following.

First, we found an emphasis on "e-learning"-particularly in Twitter and Facebook posts-as well as "blended learning" (Twitter) and "online learning" (journal articles). Notably, COVID-19 (and related terms) were also frequently mentioned. These findings align with how mentions of "e-learning" spiked during the 2020 year when the effects of the COVID-19 pandemic on education were especially disruptive, but their ongoing presence also suggests that interest in these topics will likely extend outside and beyond the context of the pandemic.

Second, we note a keen interest in emergent technologies like artificial intelligence and virtual reality, particularly on the part of researchers (as evidenced by how frequently these terms were mentioned in journal articles published in 2021). At the same time, we note that this interest has not yet crystallized into the sustained adoption and use of these 
emergent technologies-a point bolstered by the relatively limited mention of these technologies in the Facebook posts of schools and school districts. Thus, we think we as a field must wait and see whether interest in these technologies is lasting or transient.

Last, we found an ever-increasing reliance on several corporate entities for productivity and sharing. This was especially the case for Google and tools created by Google: YouTube, Google Docs, and Google Drive, in particular. Indeed, such tools are such an established part of our work (and educational) context that we might hardly think of them as tools. Furthermore, tools created by Google and several other corporations-including social media platforms themselves-were also prevalent in the content of the tweets we analyzed. While we do not believe it is a bad decision on the part of individuals or educational institutions to use these and other tools, there are also some potential downsides to their use that we think invite critical questions (Burchfield et al., 2021; Krutka et al., 2021).

As a result of these common takeaways, we will now conclude with three questions for educational technology researchers and practitioners to consider.

\section{Pandemic Bump Vs. Ubiquity}

First, many have wondered whether changes in educational technology catalyzed by the pandemic will yield sustained, ubiquitous changes to the field, or if adjustments represent only a short-term bump of interest - as may be the case with emergency remote teaching tools and strategies used in the early days of the pandemic (Hodges et al., 2020). One of the takeaways from our Facebook analysis was that while some productivity technologies appeared to have remained consistently used on the basis of our domain analysis (e.g., Google Docs), mentions of many specific technologies in the messages of the posts by schools and districts appeared to have been more transitory in nature, such as in the cases of "e-learning" and "learning management systems." This suggests at least two possible interpretations. One is that these technologies were used in transient response to an unprecedented period of emergency remote instruction-though tools associated with remote teaching and learning continue to be used, their use was primarily a temporary, emergency measure. Another is that these tools were mentioned less because they have become a more ubiquitous but less visible tool used by teachers and learners. Learning management systems may still, of course, be widely used, but schools and districts may be sharing about their role less through their public social media platforms because they may already be familiar to students and their parents. While we cannot say why there was a dramatic increase followed by a decrease in the use of many educational technologies over the period from 2019 through 2021, our analysis indicates that many tools are, at least, being communicated about much less over the past year than in the preceding year when the pandemic began in the U.S.

\section{Technocentrism Vs. Focusing on Learners and Improving Educational Systems}

Second, though emerging technologies are obviously an essential component of our field, one of the perennial challenges we must grapple with is our relationship to these technologies. Are we technocentric, as Papert $(1987,1990)$ warned, or do we focus on learning and improvement? In our results, we notice that technologies such as artificial intelligence, virtual reality, and augmented reality were very frequently referenced in comparison to most other modalities or topics of research. As processing and graphical rendering capabilities continue to become more compact and inexpensive via headsets, smartphones, and haptic devices, we would expect these technologies to continue to receive ongoing attention. Though there are certainly valuable learning improvement opportunities associated with such technologies (Glaser \& Schmidt, 2021), we might also justifiably wonder whether the volume of attention that these technologies are currently receiving in the literature is concomitant to their actual (or even hypothetical) largescale learning benefits-or whether current fascination with such technologies represents a repeat of other historical emphases that may not have panned out in the form of systemic educational improvement, such as in the case of MUVEs (cf., Nelson \& Ketelhut, 2007).

\section{Limited Broader Impacts on Larger Social Issues}

Finally, to reiterate our critiques from previous years (Kimmons, 2020; Kimmons et al., 2021), we continued to see a dearth of references to important social issues in scholarly article titles, including references to social matters upon which educational technology should be expected to have a strong voice. For instance, terms relating to universal design $(n=0)$, accessibility $(n=4)$, privacy $(n=8)$, ethics $(n=12)$, security $(n=8)$, equity $(n=6)$, justice $(n=1)$, and (digital and participatory) divides $(n=1)$ were all very uncommon. Though "ethics" was the most common of these terms, it only was represented in 1-in-200 article titles, and though current "practices with student data represent cause for concern, as student behaviors are increasingly tracked, analyzed, and studied to draw conclusions about learning, attitudes, and future behaviors" (Kimmons, 2021, para. 2; cf., Rosenberg et al., 2021) and proctoring software becomes increasingly ubiquitous (Kimmons \& Veletsianos, 2021), "privacy" was only mentioned in 1-in-333 article titles and "proctor*" was only in 1-in-600 titles. In our current pandemic context, we have often heard educational technologists lament the fact 
that decision-makers and those in power may not seek our guidance in addressing issues related to the pandemic that would clearly benefit from our expertise. And yet, the absence of other socially-relevant topics from our research suggests that we may be challenged to leverage our work toward addressing matters of larger social or educational importance ourselves. A focus on the social matters and the social context around educational technology use, then, remains an opportunity for research and development by the educational technology community in the years ahead. This seems especially salient as our data suggests that the field is heavily influenced by big technology corporations like Google and Facebook that historically have been critiqued for violating ethical expectations of privacy and failing to support social good. As educational technology researchers and practitioners, we are primed with the position and expertise necessary to shape the future of ethical technology use in education. Hopefully, we can step up to this challenge.

\section{References}

Carpenter, J. P., \& Krutka, D. G. (2014). How and why educators use twitter: A survey of the field. Journal of Research on Technology in Education, 46(4), 414-434.

Glaser, N., \& Schmidt, M. (2021). Systematic literature review of virtual reality intervention design patterns for B with autism Spectrum disorders. International Journal of Human-Computer Interaction, 1-36.

Hodges, C.B., Moore, S., Lockee, B.B., Trust, T., \& Bond, M. A. (2020). The difference between emergency remote teaching and online learning. EDUCAUSE Review. https://er.educause.edu/artic les/2020/3/the-difference-between-emergency-remote-teachingand-online-learning

Kimmons, R. (2020). Current trends (and missing links) in educational technology research and practice. TechTrends, 64(6). https://doi. org/10.1007/s11528-020-00549-6.

Kimmons, R. (2021). Safeguarding student privacy in an age of analytics. Educational Technology Research \& Development, 69, 343-345. https://doi.org/10.1007/s11423-021-09950-1

Kimmons, R., \& Veletsianos, G. (2018). Public internet data mining methods in instructional design, educational technology, and online learning research. TechTrends, 62(5), 492-500. https:// doi.org/10.1007/s11528-018-0307-4
Kimmons, R., \& Veletsianos, G. (2021). Proctoring software in higher ed: Prevalence and patterns. EDUCAUSE Review. https://er.educa use.edu/articles/2021/2/proctoring-software-in-higher-ed-preva lence-and-patterns

Kimmons, R., Veletsianos, G., \& VanLeeuwen, C. (2020). What (some) faculty are saying about the shift to remote teaching and learning. EDUCAUSE Review. https://er.educause.edu/blogs/2020/5/ what-some-faculty-are-saying-about-the-shift-to-remote-teach ing-and-learning

Kimmons, R., Rosenberg, J., \& Allman, B. (2021). Trends in educational technology: What Facebook, twitter, and Scopus can tell us about current research and practice. TechTrends, 65, 125-136. https://doi.org/10.1007/s11528-021-00589-6

Krutka, D. G., Smits, R. M., \& Willhelm, T. A. (2021). Don't be evil: Should we use Google in schools? TechTrends, 65(4), 421-431.

Michela, E., Rosenberg, J. M., Kimmons, R., Sultana, O., Burchfield, M. A., \& Thomas, T. (2022). "We are trying to communicate the best we can": Understanding districts' communication on Twitter during the COVID-19 pandemic. AERA Open. https://osf.io/ qpu $8 \mathrm{v} /$

Nelson, B. C., \& Ketelhut, D. J. (2007). Scientific inquiry in educational multi-user virtual environments. Educational Psychology Review, 19(3), 265-283.

Papert, S. (1987). Computer criticism vs. technocentric thinking. Educational Researcher, 16(1), 22-30.

Papert, S. (1990). A critique of technocentrism in thinking about the school of the future. MIT Epistemology and Learning Memo No. 2. Cambridge, Massachusetts: Massachusetts Institute of Technology Media Laboratory.

Rosenberg, J. M., Greenhalgh, S. P., Koehler, M. J., Hamilton, E. R., \& Akcaoglu, M. (2016). An investigation of state educational twitter hashtags (SETHs) as affinity spaces. E-learning and Digital Media, 13(1-2), 24-44.

Rosenberg, J. M., Burchfield, M., Borchers, C., Gibbons, B., Anderson, D., \& Fischer, C. (2021). Social media and students' privacy: What schools and districts should know. Phi Delta Kappan, 103(2), 49-53.

Trust, T., Carpenter, J., Krutka, D. G., \& Kimmons, R. (2020). \#RemoteTeaching \& \#RemoteLearning: Educator tweeting during the COVID-19 pandemic. Journal of Technology and Teacher Education, 28(2), 151-159.

Veletsianos, G., \& Kimmons, R. (2020). What (some) students are saying about the switch to remote teaching and learning. EDUCAUSE Review. https://er.educause.edu/blogs/2020/4/what-some-stude nts-are-saying-about-the-switch-to-remote-teaching-and-learning

Weller, M. (2020). 25 years of ed tech. Athabasca University Press.

Publisher's Note Springer Nature remains neutral with regard to jurisdictional claims in published maps and institutional affiliations. 